\title{
FUZZY LOGIC APPROACH TO ASSESS BIOLOGICAL QUALITY
}

\section{ARIF KHAN}

\author{
Principal, NCET, Kalmeshwar, Nagpur-MH, India
}

Biodiversity indices developed have been used to find plant biodiversity index, bird biodiversity index and aquatic biodiversity index, independently. However, a single index is not available to represent biological environment in a nutshell, which can represent aquatic biodiversity, plant biodiversity and bird biodiversity index. Moreover, in development of these indices, Crisp Set Theory has been used, which deals with standing boundary conditions. In present paper, an attempt has been made to develop single index, which can represent biological environment at a glance, by using fuzzy set theory.
\end{abstract}

KEYWORDS: Biodiversity Index, Fuzzy Biodiversity Index, Fuzzy Set Theory \& Shannon Wiener Index

Received: Jun 22, 2017; Accepted: Jul 10, 2017; Published: Jul 18, 2017; Paper Id.: IJCSEIERDAUG20173

\section{INTRODUCTION}

In ecological system aquatic living organisms, non aquatic living organisms and other living organisms form a complex and variable relation, within their own species and with other species too, which is defined as biodiversity. It is a term used to describe the variety of life on earth. It refers to the wide variety of ecosystems and living organisms: animals, plants and their habitats. [3]

The execution of ecosystem depends upon biodiversity. Human life is dependent on biodiversity for survival. We depend on it, for the products for our consumption and for the consumption of other living organisms too. We are also dependent on it for services. Nature gives us air to breath, food and water for survival, and shelter. Protection from natural calamities and stable climatic conditions can be achieved if the biodiversity of the system is rich. For our security and good health also, we depend upon our ecosystem. No one can live, if biodiversity is poor [5]. By changing the stability of biodiversity, we strongly affect human well-being and the well-being of every other living being.

Every decision that affects biodiversity, would affect our lives and the lives of other people. Biodiversity is crucial to human well being, sustainable development and poverty reduction. An ecosystem assessment report says that, we have 5000000 to 30000000 species on earth and out of which, only 1700000 to 2000000 have been identified [7].

\section{CRISP BIODIVERSITY INDEX}

A diversity index is a mathematical measure of species diversity, in a community. Diversity indices provide more information about community composition than simply species richness i.e., the number of species present [3]. The Shannon-Wiener Index is one of the several diversity indices used to measure diversity.

Shannon-Wiener Index is commonly used, in the measurement of biodiversity. The advantage of this 
index is that, it takes into account the number of species and the evenness of the species. Typically the value of the index ranges from 1.5 (low species richness and evenness) to 5.0 (high species evenness and richness), though values beyond these limits may be encountered. Measurements of diversity have been of historical significance and their importance remains even today [7]. It is derived from a function used in the field of information and has been adapted by ecologists, to describe the average degree of uncertainty of predicting the species of an individual, picked at random from the community. The uncertainty of occurrence increases both as the number of species increases and as the individuals are distributed more and more evenly, among the species that are already present.

\section{Measuring Biodiversity of Ecological Communities}

Quantifying biodiversity is an issue of concern, among ecologists. However, its quantification is complicated. It needs a complex statistical analysis, as it depends on total number of species present and their relative predominance [7]

On the basis of this, many indices have been developed to measure the biodiversity. Shannon Wiener Index and Simson Index are most common indices used for measuring biodiversity.

In most ecological studies typical values of biodiversity lies between 1.5 to 3.5 and very rarely it go up to 4 . Indices developed have been used to find plant biodiversity index, bird biodiversity index and aquatic biodiversity index independently. However, a single index is not available to represent biological environment in a nutshell, which can represent aquatic biodiversity, plant biodiversity and bird biodiversity index. In present paper an attempt had been made, to develop single index, which can represent biological environment at a glance, by using fuzzy set theory.

Fuzzy set was first introduced by Lotfi Zadeh (1965) and is considered as advancement of crisp theory. A fuzzy number differs from crisp number, in terms of its membership value within the domain. In classical set theory (crisp number system), the membership function of a number is 1 , within the boundaries of the set and is 0 outside. A fuzzy number may have several different membership values, within an interval of 0 and 1. [1] The membership functions represent the degree, to which the specified value belongs to the set. If membership is close to 1, the more likely it belongs to the set; on the other hand, the closer it is to 0, the less it belongs to the set [6].

\section{DEVELOPMENT OF FUZZY BIODIVERSITY INDEX (FBDI)}

\section{Quantification of Biodiversity to Find Fuzzy Biodiversity Index (FBDI)}

Fuzzy Biodiversity Index (FBDI) is calculated by using fuzzy inference technique, to obtain a single value to represent biological environment i.e., Fuzzy and Biological Quality Index FBQI.

\section{Model Development to Find Fuzzy Biodiversity Index (FBDI)}

For Environmental Impact Assessment studies of plant biodiversity index, bird biodiversity index and aquatic biodiversity index are calculated, by using Shannon-Wiener index. In the present study, the index value obtained by using Shannon-Wiener index has been used, to obtain a common biodiversity index representing plant biodiversity, bird biodiversity and aquatic biodiversity.

The crisp index value (Shannon-Wiener index) is classified in three categories desirable, acceptable and unacceptable, for generating their membership function for input variable 'plant biodiversity', 'bird biodiversity' and 'aquatic biodiversity'. In the next step, these values were evaluated by using fuzzy inference system and final result was obtained, which was further defuzzified to find Fuzzy Biodiversity Index (FBDI). 
Plant biodiversity, bird biodiversity and aquatic biodiversity were selected as an input variable, to find Fuzzy Biodiversity Index. The nature of the curve for membership functions, were considered trapezoidal. For example, membership function for Plant biodiversity, linguistic variable "Acceptable" has four values in parameter column i.e., 1.5, 2, 3.5, 4 that represents that, truth value (membership function) varies from 0 to 1 , for 1.5 to 2 , between 2 to 3.5 it is 1 and between 3.5 to 4 , it varies between 1 to 0 .

\section{Input Variables with their Membership Function}

- $\quad$ Plant Biodiversity Index.

- $\quad$ Bird Biodiversity Index.

- $\quad$ Aquatic Biodiversity Index.

Table 1: Membership Function for Plant BDI, Bird BDI \& Aquatic BDI

\begin{tabular}{|c|l|c|}
\hline Sr. No. & $\begin{array}{c}\text { Membership Function for Plant BDI, Bird BDI \& } \\
\text { Aquatic BDI }\end{array}$ & Shannon-Wiener Index \\
\hline 1 & Desirable & {$[0,0,1.5,2]$} \\
\hline 2 & Acceptable & {$[1.5,2,3.5,4]$} \\
\hline 3 & Unacceptable & {$[3.5,4,7,7]$} \\
\hline
\end{tabular}

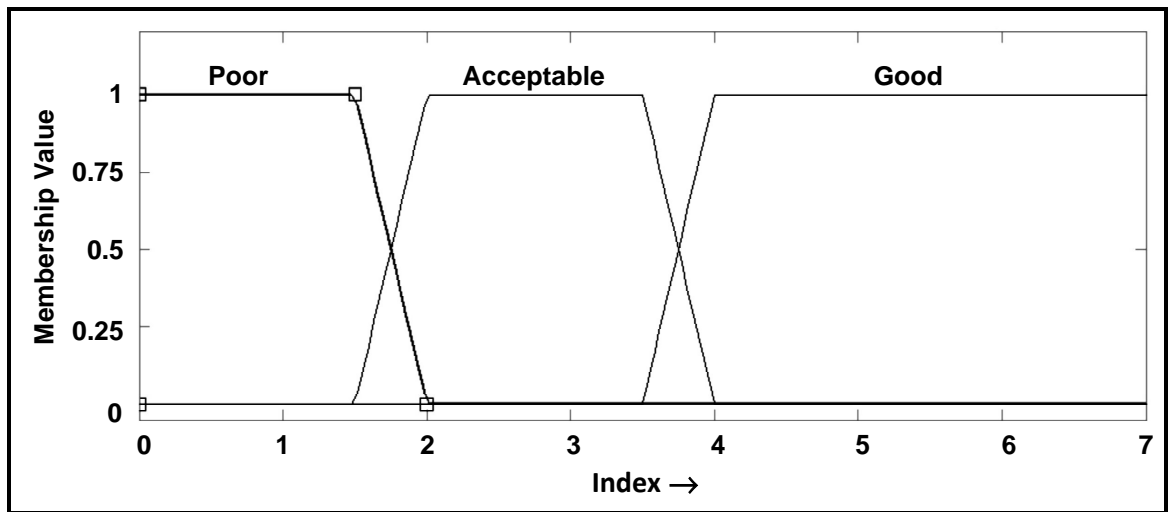

Figure 1: Fuzzy Set for "Bird Bdi" “Plant Bdi”'\& "Aquatic Bdi”

\section{Output (FBDI) with its Membership Function}

Fuzzy Biodiversity Index (FBDI)

Table 2: Membership Function for FBDI

\begin{tabular}{|c|l|c|}
\hline Sr. No. & Membership Function for FBDI & Defuzzified Index \\
\hline 1 & Desirable & {$[0,0,1.5,2]$} \\
\hline 2 & Acceptable & {$[1.5,2,3.5,4]$} \\
\hline 3 & Unacceptable & {$[3.5,4,7,7]$} \\
\hline
\end{tabular}




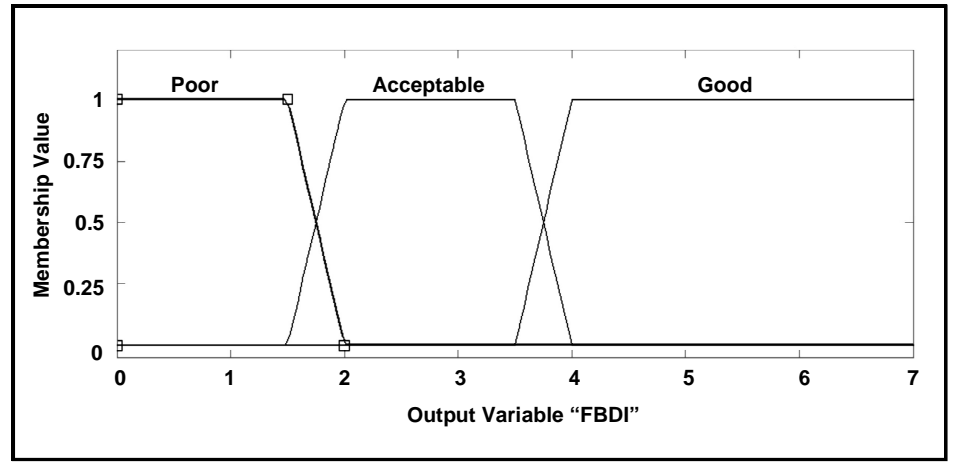

Figure 2: Fuzzy Set for Variable "FBDI"

The biodiversity can be classified based on Shannon-Wiener index, of any input variable. For example, based on the concentration of plant biodiversity, biological quality can be defined as Desirable, Acceptable, and Unacceptable. It can be seen in Figure 1 that, the fuzzy set of plant biodiversity for acceptable biological environment, varies from 1.5 to 4 . The first value (1.5) is the minimum with zero membership value, next 2 with unit membership value, which extends up to 3.5 and then the membership value falls down to zero, at 4. The membership function for this set, is shown on Y axis. It is evident that, the value 3.8 is in both the sets: Acceptable and Unacceptable, but its degree of membership in both the set varies. This kind of classification is more pertinent for describing the biological environment, as it takes variability into consideration. Certainly, the traditional classical set cannot take into account, variability/subjectivity of information into the procedure. Similarly fuzzy set of FBDI is shown in Figure 2.

\section{Rules to Obtain FBDI}

In the crisp set based FBDI system, the value of index is determined by algebraic operations of individual parameter values, using a derived mathematical expression, which is then transformed into informative descriptors. In a fuzzy rule based system, the numerical value of FBDI is determined by rules, based on expert knowledge. Each rule has a set of antecedent's propositions, comprising of attributes for input variables. Attributes are linguistic expressions like Desirable, Acceptable and Unacceptable. These linguistic descriptions are invariably imprecise, keeping in view of the inadequate information on the health implication of each parameter, on the ecosystem and the integrated effect of all the parameters, on the environment. The rules formed to find FBDI, are shown in Table 3.

Table 3: Rules to Determine FBDI

\begin{tabular}{|l|l|l|l|l|l|l|}
\hline & \multicolumn{3}{|c|}{ IF } & \multicolumn{1}{c|}{ THEN } \\
\hline Rule & \multicolumn{1}{|c|}{ Plant_BDI } & & \multicolumn{1}{|c|}{ BIRD_BDI } & & Aquantic_BDI & FBDI \\
\hline 1. & Poor & $A N D$ & Acceptable & $A N D$ & Not Poor & Acceptable \\
\hline 2. & Poor & - & - & $A N D$ & Poor & Poor \\
\hline 3. & Poor & - & - & $A N D$ & Poor & Poor \\
\hline 4. & Poor & $A N D$ & Acceptable & $A N D$ & Not Poor & Acceptable \\
\hline 5. & Poor & $A N D$ & Good & $A N D$ & Acceptable & Acceptable \\
\hline 6. & Poor & $A N D$ & Good & $A N D$ & Good & Good \\
\hline 7. & Acceptable & $A N D$ & Poor & $A N D$ & Not Poor & Acceptable \\
\hline 8. & Acceptable & $A N D$ & Acceptable & $A N D$ & Not Good & Acceptable \\
\hline 9. & Acceptable & $A N D$ & Acceptable & $A N D$ & Good & Good \\
\hline 10. & Acceptable & $A N D$ & Good & $A N D$ & Poor & Acceptable \\
\hline 11. & Acceptable & $A N D$ & Good & $A N D$ & Not Poor & Good \\
\hline 12. & Good & $A N D$ & Poor & $A N D$ & Not Poor & Acceptable \\
\hline 13. & Good & $A N D$ & Acceptable & $A N D$ & Poor & Acceptable \\
\hline
\end{tabular}




\begin{tabular}{|l|l|l|l|l|l|l|}
\hline 14. & Good & $A N D$ & Acceptable & $A N D$ & Not Poor & Good \\
\hline 15. & Good & $A N D$ & Good & - & - & Good \\
\hline
\end{tabular}

Rule based fuzzy inference system, for the FBDI model and its surface generated are shown in Figure 3 and Figure 4, respectively. The first step is to identify all the rules in which, each parameter value falls. Based on these membership values and operators (OR / AND), the output fuzzy set was implicated. The implicated output from each rule was then aggregated and defuzzified, to obtain the value of FBDI and its class.

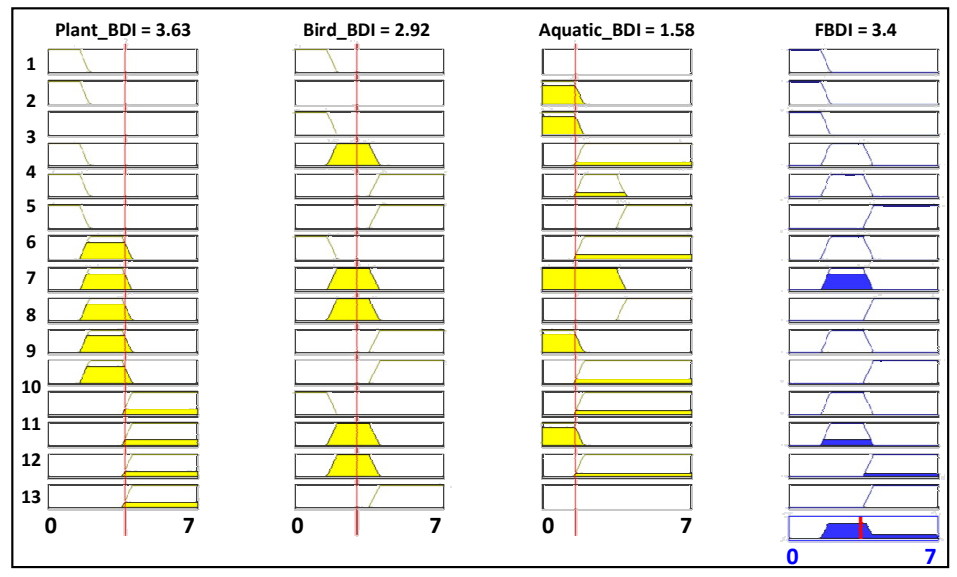

Figure 3: Rule View for Rule Based "FBDI"

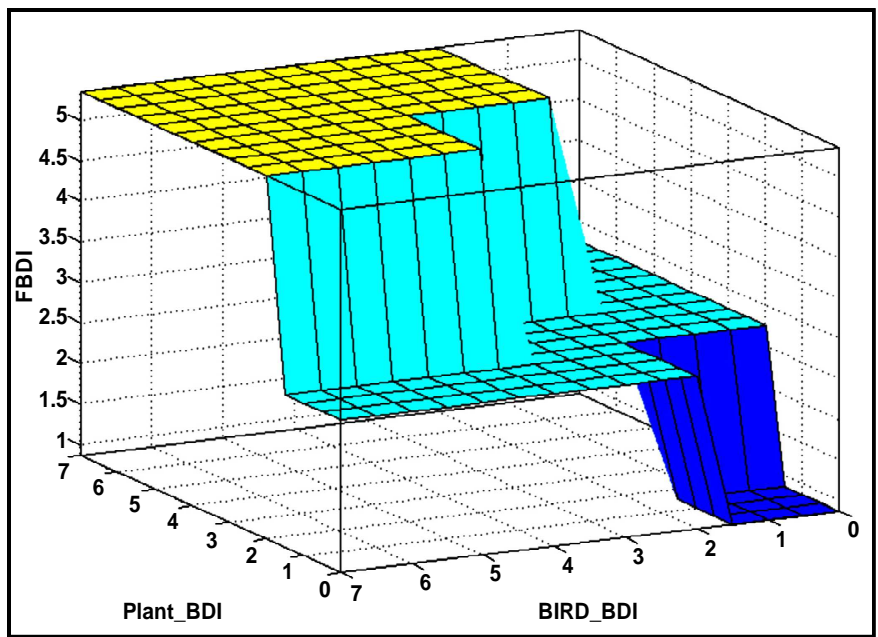

Figure 4: Surface Generated For FBDI by Rule Based Fuzzy Inference System

\section{CONCLUSIONS}

Traditionally biodiversity indices developed have been used to find plant biodiversity index, bird biodiversity index and aquatic biodiversity index, independently. However, a single index is not available to represent biological environment in a nutshell, which can represent aquatic biodiversity, plant biodiversity and bird biodiversity index. All these biodiversity indices are based on crisp set theory, which deals with standing boundary conditions. Present study has been made, to develop single index which can represent biological environment at a glance, by using fuzzy set theory. The nomenclature of new index is termed as, Fuzzy Biodiversity Index (FBDI). 


\section{REFERENCES}

1. Arif Khan, Fuzzy Logic Approach to Quantify Water Pollution” International Journal of Engineering Science and Computing, IJESC, ISSN 2321 3361, IF 5.611, Volume 7, Issue No. 5, May 2017

2. Bart Kosko, 1993, Fuzzy Thinking: The New Science of Fuzzy Logic, Prentice-Hall, US.

3. Edward O. Wilson The Diversity of Life - With a New Preface (Questions of Science) Paperback - 5 Nov 2010, Amazon Kindle.

4. George K.V., Arif Khan, Proceedings of the 4th Indian International Conference on Artificial Intelligence, IICAI 2009, Tumkur, Karnataka, India, December 16-18, 2009. IICAI 2009, ISBN 978-0-9727412-7-9

5. Kevin J. Gaston, John I. Spicer, Biodiversity: An Introduction, 2nd Edition December 2003, @2004, Wiley-Blackwell

6. Klir, G.J., Yuan, B., 2006. Fuzzy sets and fuzzy logic, Theory and applications. Prentice-Hall of India, New Delhi.

7. Magurran, A.E. 2004. Meausuring Biological Diversity. Blackwell.

8. Zadeh L.A., 1973, The concept of linguistic variable and its application to approximate reasoning. Memorundum ERL-M411, Berkeley, October 1973. 